\title{
Consumption of Buckwheat Products and Cardiovascular Risk Profile: A Randomized, Single-Blinded Crossover Trial
}

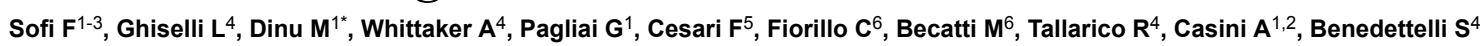

${ }^{1}$ Department of Experimental and Clinical Medicine, School of Human Health Sciences, University of Florence, Italy

${ }^{2}$ Unit of Clinical Nutrition, Careggi University Hospital, Florence, Italy

${ }^{3}$ Don Carlo Gnocchi Foundation Italy, Onlus IRCCS, Florence, Italy

${ }^{4}$ Department of Agrifood Production and Environmental Sciences, University of Florence, Italy

${ }^{5}$ Unit of Atherothrombotic Diseases, Careggi University Hospital, Florence, Italy

${ }^{6}$ Department of Clinical and Experimental Biomedical Sciences, University of Florence, Italy

*Corresponding author: Dinu M, Department of Experimental and Clinical Medicine, University of Florence Largo Brambilla, 350134 Florence, Tel: 3905527571 ; Email: mdinu@unifi.it

Received date: February 29, 2016; Accepted date: April 29, 2016; Published date: May 6, 2016

Copyright: (c) 2016 Sofi F, et al. This is an open-access article distributed under the terms of the Creative Commons Attribution License, which permits unrestricted use, distribution, and reproduction in any medium, provided the original author and source are credited.

\begin{abstract}
Background: Lifestyle modifications, especially dietary interventions, assume an increasingly more important role in the population-based approach to cardiovascular diseases risk reduction. Buckwheat is a highly nutritional food component that has been shown to provide a wide range of beneficial effects.

Objective: The aim of the study was to examine whether a replacement diet with buckwheat products could provide additive protective effects in reducing cardiovascular risk factors, including blood glucose, insulin, lipids, oxidative damage and pro-inflammatory markers, in comparison to a similar replacement diet using products made from organic wheat.

Methods: Twenty-one participants at high risk for cardiovascular disease (11 F; $10 \mathrm{M}$; mean age $51.3 \pm 13.4$ ) were randomized to receive products (bread, pasta, biscuits and crackers), made from either buckwheat-enriched semi-wholegrain wheat or control semi-wholegrain wheat for 8 weeks in a single-blinded crossover trial. A washout period of 8 weeks was implemented between the two intervention phases, in which participants were permitted to eat all foods according to their normal eating habits. Blood analyses were performed at the start and end of each intervention period, respectively.
\end{abstract}

Results: Consumption of buckwheat products resulted in a significant amelioration in total cholesterol (-4.7\%), low-density lipoprotein cholesterol $(-8.5 \%)$, triglycerides $(-15 \%)$, glucose $(-5.8 \%)$ and insulin $(-17 \%)$ from baseline levels, independently of age, sex, body mass index and hypertension. Moreover, thiobarbituriic acid reactive substances (TBARs) levels were significantly reduced by $29.5 \%$. A concomitant significant increase in plasma ORAC levels $(+9.7 \%)$ was observed. No significant differences from baseline in the same participants were observed after consumption of the control products.

Conclusion: Our results suggest that a replacement diet with buckwheat products exert a protective effect on the development of cardiovascular disease by reducing circulating cardiovascular risk factors and markers of oxidative stress.

Keywords: Buckwheat; Cardiovascular disease; Risk; Biomarkers

\section{Abbreviations}

AAPH: 2,2-Azobis(2-Amidinopropane) Dihydrochloride; ARP: Antiradical Power; BMI: Body Mass Index; CVD: Cardiovascular Diseases; DPPH: 2,2-Diphenyl-1-Picrylhydrazyl; HOMA: The Homeostasis Model Assessment; MCP-1: Monocyte Chemotactic Protein-1; MIP-1 beta: Macrophage Inflammatory Protein-1 beta; ORAC: Oxygen Radical Absorbance Capacity; ROS: Reactive Oxygen Species; TAC: Total Antioxidant Capacity; TBARs: Thiobarbituric Acid Reactive Substances; TNF-alpha: Tumour Necrosis Factor-alpha; VEGF: Vascular Endothelial Growth Factor

\section{Introduction}

Worldwide morbidity and mortality from infectious diseases is being replaced by chronic diseases, commonly referred to as noncommunicable diseases, of which cardiovascular diseases (CVD) account for the majority of existing deaths. [1-3] Diet and nutrition are important factors in the promotion and maintenance of good health, and an unhealthy diet represents a modifiable, behavioural risk factor that impacts on the global risk profile, resulting in the progression of chronicdisease. [3] Hence, nutritional research has shifted from focusing predominantly on alleviating nutrient deficiencies to include chronic disease prevention [1]. 
Cereals and pseudo cereals represent an excellent source of dietary energy for humans, and in most countries and regions, form the major dietary component. Common buckwheat (Fagopyrum esculentum), a gluten-free pseudo cereal, which, besides being recognized as a nutritionally valuable source of protein, lipid, dietary fibre and minerals, is receiving increased attention as a potential functional food $[4,5]$. The cardiovascular, anti-cancer and anti-diabetic health benefits attributed to buckwheat have been associated with improved antioxidant, hypocholesterolemic and hypoglycemic effects, as reported from studies conducted predominantly on animal models and in vitro experiments. $[4,5]$.

To date, relatively few studies have been conducted on humans. [5] It is noteworthy that in a large trial conducted by Zhang et al. [6], lifelong consumption of buckwheat as a staple food was associated with lower hypertension, dyslipidaemia, and hyperglycaemia. Of interest, besides the low number of studies conducted on humans, an insufficient number of studies have been performed on the antiinflammatory activity of buckwheat, thereby making it difficult to draw conclusions on these parameters.

The objective of the present work was to investigate whether buckwheat consumption in a healthy Italian population, but with a high risk for cardiovascular problems, was specifically associated with improvements in CVD risk profile by examining lipid, glucose and oxidative parameters, as well as inflammatory parameters.

\section{Materials and Methods}

\section{Study population}

Twenty-one individuals (11 women and 10 men) were recruited from the Unit of Clinical Nutrition of the Department of Experimental and Clinical Medicine, University of Florence, Careggi University Hospital. Participants were eligible if they were older than 18 years and fulfilled $>1$ of the following criteria: being overweight (Body Mass Index $>25.1 \mathrm{~kg} / \mathrm{m}^{2}$ ) and by the concomitant presence of at least one the following criteria:

- Circulating levels of total cholesterol $>190 \mathrm{mg} / \mathrm{dL}$, not on drug treatment (measured no more than 3 months prior to the start of the study).

- Circulating levels of LDL cholesterol $>115 \mathrm{mg} / \mathrm{dL}$, not on drug treatment (measured no more than 3 months prior to the start of the study).

- Circulating levels of triglycerides $>150 \mathrm{mg} / \mathrm{dL}$, not on drug treatment (measured no more than 3 months prior to the start of the study).

- Circulating levels of fasting blood glucose $>110 \mathrm{mg} / \mathrm{dL}$ but $<126$ $\mathrm{mg} / \mathrm{dL}$, not on drug treatment (measured no more than 3 months prior to the start of the study).

Criteria for exclusion included a history of serious medical conditions including diabetes, liver diseases, renal diseases and cancer, the adherence to a specific diet or other medically prescribed diets, gluten and buckwheat allergies, gastrointestinal disorders (e.g. inflammatory bowel disease, irritable bowel syndrome or other chronic gastrointestinal complaints), alcohol or drug abuse, pregnancy, lactation and an unstable medical status. Individuals with a recent episode of myocardial infarction, stroke, or any other severe pathology, considered to pose a risk to the individual or to confound the results of the study, were all excluded. After explaining the protocol to the participants and obtaining written informed consent, a precise medical history was obtained from each individual.

\section{Experimental and control wheat}

The common buckwheat (Fagopyrum esculentum Moench.) variety Lileja, utilized as the experimental grain in the present project. The latter was cultivated in the Italian province of Umbria and obtained through the project entitled "Saraceno-Umbria" Act 1.2.4 PSR under Umbrian Regional law. Cultivation was under organic conditions, in that no fertilizers or pesticides were used. The dehulled seeds (raw groats) were stone-milled at the Molino Marini (Foligno, Perugia). Since different countries utilize different terminology to classify the different types of milled flour, we report the ash content (positively correlated to the extraction rate) for comparative purposes. The experimental buckwheat had an ash content of 1.35\%-1.49\%, and was considered "wholegrain". As the control (from here on referred to as the control wheat), a mix of organic commercial Italian durum (Triticum durum Desf.) varieties and soft wheat (Triticum aestivum L.) varieties, respectively, were used. Semi-wholegrain granulated semolina (ash content 1.0\%-1.35\%) and semi-wholegrain flour (ash content, $0.95 \%$ ), respectively, were processed by Molino SIMA.

For the buckwheat-enriched pasta, 50\% wholegrain buckwheat flour was blended with $50 \%$ semi-wholegrain granulated semolina. Pastificio Artigiano FABBRI s.a.s. (Strada in Chianti, Firenze, Italy) prepared the pasta (with no additives) from both the buckwheat-enriched and control semolina, according to the artisan manufacturing procedures. For baking purposes, $40 \%$ wholegrain buckwheat flour was mixed with the semi-wholegrain flour. Panificio Menchetti Pietro di Santi e Figli s.n.c. (Cesa Marciano della Chiana, Arezzo, Italy), an artisan enterprise was responsible for the preparation of the bread, biscuits and crackers using both the buckwheat-enriched and control flour. Naturally, leavened Tuscan-style sourdough bread was prepared. Besides the flour composition, dry crackers contained $20 \%$ extra-virgin olive oil. The biscuits were prepared using $10 \%$ sugar, $5 \%$ butter, and one egg per $100 \mathrm{~g}$ flour.

\section{Study protocol}

The study was a randomized, single blinded, cross-over trial to test the effect of a replacement diet with buckwheat products on markers related to cardio-metabolic risk. The experimental products were compared with a similar replacement diet using organic semi-whole grain products. The participants were randomly assigned, using a computerized random number generator, to one of two treatment orders starting with buckwheat products or control products, respectively. Each dietary phase lasted 8 weeks with an 8 week washout period. After the wash-out period, participants were crossed over to the opposite treatment.

The enrolled subjects were examined four times during the study, one before and one after each intervention period. During each clinical visit, fasting body weight was recorded and BMI was calculated as weight $(\mathrm{kg}) /$ height $(\mathrm{m})^{2}$. Peripheral venous blood was drawn between 07:00-09:30 h after a $12 \mathrm{~h}$ fasting period. One day before each examination, subjects were asked to refrain from engaging in any strenuous exercises. Furthermore, the participants were asked not to alter their physical activity habits during the study. A baseline questionnaire indicated that $14 \%$ of the subjects had physical activity levels equivalent to $30-60 \mathrm{~min} / \mathrm{d}$ and $86 \%$ reported to have a sedentary lifestyle. 
The buckwheat or control products provided for the 8 week intervention periods were as follows: $500 \mathrm{~g}$ per week of pasta, $1 \mathrm{~kg}$ per week of bread, $500 \mathrm{~g}$ per month of crackers and $1 \mathrm{~kg}$ per month of biscuits. During the intervention phases, all participants were not permitted to eat other grains products, whereas when on the wash-out period, they were encouraged to eat "as usual". To ensure consumption of the products provided and the maintenance of usual lifestyle habits, the researcher interacted with the participants on a weekly basis.

The present study was conducted according to the guidelines, prescribed by the Declaration of Helsinki, and the local ethic committee approved the protocol. Written informed consent was obtained from all the subjects. Recruitment began in September 2014, and the experimental trials took place between January 2015 and June 2015.

\section{Physiological parameters of the buckwheat and control}

Total polyphenol content, total anti-radical power (ARP, using the DPPH method) and the mineral element content were measured as previously described [7].

\section{Blood measurements}

After an overnight fasting for 10-12 h, a venous blood sample was obtained from each subject. Serum was separated after centrifuging at $3000 \times \mathrm{g}$ for $15 \mathrm{~min}$ at $4^{\circ} \mathrm{C}$. Samples were stored in aliquots at $-80^{\circ} \mathrm{C}$ until analysis. Lipid variables, blood glucose and serum electrolytes were assessed by conventional methods. Pro- and anti-inflammatory cytokines were determined by using the Bio-Plex cytokine assay (BioRad Laboratories Inc., Hercules, CA, USA), according to manufacturer's instructions.

\section{Assessment of ROS production and total antioxidant capacity}

The measurement of leukocyte (lymphocyte, monocyte and granulocyte) ROS generation was performed as described previously $[7,8]$. Similarly, the thiobarbituric acid reactive substance (TBARS) assay kit (Oxitek-ZeptoMetrix Corporation Buffalo, NY, USA) was used to measure fatty acid peroxidation. Total Antioxidant Capacity (TAC), accounting for total hydrophilic ROS scavengers, was measured using the ORAC assay (Oxygen Radical Absorbance Capacity). The determination was based on the inhibition of the peroxyl-radicalinduced oxidation initiated by thermal decomposition of azocompounds, such as 2,2-azobis(2-amidinopropane) dihydrochloride (AAPH), as reported previously [8].

\section{Statistical analysis}

The SPSS software version 20 was used to statistically analyse all data. Results were expressed as means with standard deviations for normally distributed variables, and as medians and ranges for nonnormally distributed data. The differences between the groups were tested by using the Mann-Whitney $U$ test. The two interventions were analysed by taking into account both periods, in the two groups of subjects, at different stages. Comparisons between the mean differences of variables in the two groups (buckwheat and control) were performed using paired t-test. A general linear model for repeated measurements, adjusted for age, gender, BMI, smoking habits, hypertension, dyslipidaemia and familial history for cardiovascular disease, was performed to compare the effect of the two treatments. One-way analysis of variance was used for testing differences between (1) buckwheat and control flour and semolina samples, respectively; (2) changes in experimental and control groups. The absolute change for each variable tested (mean value at baseline subtracted from the mean value after intervention for each subject) was estimated with independent $t$ sample tests. A P value of $\leq 0.05$ was considered significant for all the analyses.

\section{Results}

\section{Characteristics of the study population}

Twenty-one subjects, with a median age of 56 years (range: 28-69) and a mean \pm SD BMI of $26.4 \pm 4.3$ were enrolled in the study (Table $1)$.

\begin{tabular}{|l|l|}
\hline Characteristic & Total $(\mathbf{n}=\mathbf{2 1})$ \\
\hline Age, median (range) & $56(28-69)$ \\
\hline Sex, (M/F) & $11 / 10$ \\
\hline BMI, mean \pm SD & $26.4 \pm 4.3$ \\
\hline Hypertension, $n(\%)$ & $3(14 \%)$ \\
\hline Dyslipidemia, $n(\%)$ & $8(38 \%)$ \\
\hline Current smokers, $n(\%)$ & $3(14 \%)$ \\
\hline Familiarity for CAD & $1(5 \%)$ \\
\hline
\end{tabular}

Table 1: Baseline characteristics of the study population. BMI=Body Mass Index; $\mathrm{SD}=$ Standard Deviation; $\mathrm{CAD}=$ Coronary Artery Disease.

Three participants were smokers during the trial, 3 were hypertensive (under an optimal therapeutic control) and 8 were dyslipidemic. At baseline, no significant differences were found between the experimental and control groups for any demographic or clinical measures (data not shown). Moreover, at the end of the intervention programme, BMI did not change significantly with respect to baseline.

\section{Physiological parameters of the buckwheat and control}

Total polyphenol content, and particularly ARP, was significantly higher in the buckwheat-enriched semolina and flour than in the respective control semolina and flour (Table 2). Moreover, $\mathrm{Ca}^{2+}, \mathrm{Fe}^{2+}$, $\mathrm{K}^{+}, \mathrm{M}^{+}, \mathrm{Na}^{+}$and $\mathrm{P}^{+}$were significantly higher in both the buckwheatenriched semolina and flour in comparison to the controls (Table 2).

\begin{tabular}{|c|c|c|c|c|c|c|}
\hline Variable & Buckwheat semolina & Control semolina & $p$ value & Buckwheat flour & Control flour & $p$ value \\
\hline Total protein, \% & $12 \pm 0.4$ & $14.3 \pm 0.4$ & 0.002 & $9.9 \pm 0.4$ & $10.3 \pm 0.08$ & 0.165 \\
\hline
\end{tabular}


Citation: Sofi F, Ghiselli L, Dinu M, Whittaker A, Pagliai G, et al. (2016) Consumption of Buckwheat Products and Cardiovascular Risk Profile: A Randomized, Single-Blinded Crossover Trial. J Nutr Food Sci 6: 501. doi:10.4172/2155-9600.1000501

Page 4 of 8

\begin{tabular}{|l|l|l|l|l|l|l|}
\hline Calcium, mg/kg & $839.9 \pm 34$ & $346.7 \pm 7.3$ & $<0.001$ & $788.4 \pm 21.2$ & $354.8 \pm 5.7$ & $<0.001$ \\
\hline Copper, $\mathrm{mg} / \mathrm{kg}$ & $6.6 \pm 0.6$ & $5.6 \pm 0.7$ & 0.133 & $5.3 \pm 0.4$ & $4.3 \pm 0.1$ & 0.014 \\
\hline Iron, $\mathrm{mg} / \mathrm{kg}$ & $48.1 \pm 7.2$ & $31 \pm 4$ & 0.023 & $41.2 \pm 5.2$ & $22.8 \pm 0.5$ & 0.004 \\
\hline Potassium, mg/kg & $3037.8 \pm 276.4$ & $1969.8 \pm 10.2$ & 0.003 & $2716.4 \pm 50.4$ & $1531.6 \pm 17.1$ & $<0.001$ \\
\hline Magnesium, mg/kg & $2002.3 \pm 161.9$ & $789.7 \pm 115.3$ & $<0.001$ & $1743.9 \pm 240.1$ & $673.1 \pm 109.2$ & 0.002 \\
\hline Manganese, mg/kg & $9 \pm 0.2$ & $11.1 \pm 0.4$ & 0.001 & $10.2 \pm 1.3$ & $15.5 \pm 1.3$ & 0.008 \\
\hline Sodium, mg/kg & $46.5 \pm 2.6$ & $11.3 \pm 2.2$ & $<0.001$ & $52.7 \pm 3.2$ & $22.9 \pm 2.2$ & $<0.001$ \\
\hline Phosphorus, mg/kg & $3329.7 \pm 374.2$ & $2432 \pm 112.8$ & 0.016 & $3035.9 \pm 202.4$ & $1613.3 \pm 41.3$ & $<0.001$ \\
\hline Zinc, $\mathrm{mg} / \mathrm{kg}$ & $22.9 \pm 3.3$ & $25.3 \pm 0.2$ & 0.277 & $20.2 \pm 1.3$ & $18.3 \pm 0.5$ & 0.077 \\
\hline Total polyphenols, mg/g DM & $4.6 \pm 0.2$ & $1.8 \pm 0.08$ & $<0.001$ & $3.8 \pm 0.2$ & $1.5 \pm 0.02$ & $<0.001$ \\
\hline ARP (antiradical power) & $30.7 \pm 2.7$ & $5.9 \pm 0.7$ & $<0.001$ & $25.1 \pm 2.1$ & $4.8 \pm 0.2$ & $<0.001$ \\
\hline
\end{tabular}

Table 2: Composition of buckwheat and control wheat (for $100 \mathrm{~g}$ ). Data are reported as mean and standard deviation. One-way ANOVA test.

\section{Biochemical variables}

In order to analyse the changes in the circulatory biochemical variables after the interventions, a general linear model adjusted for age, gender, BMI, smoking habits, hypertension, dyslipidaemia and familial history for cardiovascular disease was performed. Adjusted values for biochemical and oxidative stress-related risk factors, before and after the dietary interventions in both groups, were reported in Table 3.

\begin{tabular}{|c|c|c|c|c|c|c|c|c|c|}
\hline \multirow{2}{*}{ Variables } & \multicolumn{3}{|l|}{ Buckwheat } & \multirow{2}{*}{$\begin{array}{l}\text { p† } \\
\text { pre }\end{array}$} & \multicolumn{3}{|l|}{ Control } & \multirow{2}{*}{$p \dagger$} & \multirow[t]{2}{*}{$\begin{array}{l}p \quad \text { for } \\
\text { change } \dagger\end{array}$} \\
\hline & pre & post & change & & post & change & & & \\
\hline \multicolumn{10}{|l|}{ Lipid profile } \\
\hline $\begin{array}{l}\text { Total cholesterol, } \\
\mathrm{mg} / \mathrm{dL}\end{array}$ & $202.2 \pm 43$ & $192.8 \pm 43.8$ * & $\begin{array}{l}-9.4 \\
(-19.9 \\
-3.9)\end{array}$ & 0 & $199.2 \pm 47.6$ & $202 \pm 39.2$ & $\begin{array}{l}2.9 \quad(-8.9 ; \\
14.6)^{\circ}\end{array}$ & 0.59 & 0.028 \\
\hline $\begin{array}{l}\text { LDL-cholesterol, } \\
\mathrm{mg} / \mathrm{dL}\end{array}$ & $121.3 \pm 41.2$ & $111.1 \pm 33.1$ * & $\begin{array}{l}-10.4 \\
(-18.2 \\
-2.5)\end{array}$ & 0.01 & $115.5 \pm 38.9$ & $118.8 \pm 36.8$ & $\begin{array}{l}3.3 \\
9.5)^{\circ}\end{array} \quad(-3.0 ;$ & 0.27 & 0.016 \\
\hline $\begin{array}{l}\text { HDL-cholesterol, } \\
\mathrm{mg} / \mathrm{dL}\end{array}$ & $62.6 \pm 23.1$ & $59.5 \pm 22.4$ * & $\begin{array}{l}-3.7(-6.13 \\
-1.1)\end{array}$ & 0.01 & $60.2 \pm 23.4$ & $60.2 \pm 23.4$ & $\begin{array}{l}0.05 \\
2.3)\end{array}$ & 0.96 & 0.068 \\
\hline $\begin{array}{l}\text { Triglycerides, } \\
\mathrm{mg} / \mathrm{dL}\end{array}$ & $112.8 \pm 57.7$ & $95.9 \pm 41.5$ & $\begin{array}{l}-17.0 \\
(-32.6 \\
-1.3)\end{array}$ & 0.03 & $113.7 \pm 72.5$ & $111.6 \pm 50.4$ & $\begin{array}{l}-2.1 \\
(-15.9 \\
11.8)\end{array}$ & 0.77 & 0.139 \\
\hline \multicolumn{10}{|c|}{ Glucometabolic profile } \\
\hline $\begin{array}{l}\text { Blood } \\
\mathrm{mg} / \mathrm{dL}\end{array}$ & $87.2 \pm 8.6$ & $82.2 \pm 8.1^{*}$ & $\begin{array}{l}-5.1 \quad(-8.4 \\
-1.7)\end{array}$ & 0.01 & $87.0 \pm 9.0$ & $85.0 \pm 8.7$ & $\begin{array}{l}-1.9 \\
0.1)\end{array} \quad(-4.0$ & 0.06 & 0.135 \\
\hline Insulin, U/L & $10 \pm 5.4$ & $8.3 \pm 4.4$ * & $\begin{array}{l}-1.7 \quad(-3.5 ; \\
0.2)\end{array}$ & 0.06 & $9.4 \pm 4.9$ & $9.9 \pm 5.7$ & $\begin{array}{l}-0.49 \\
(-0.57 \\
1.54)^{\circ}\end{array}$ & 0.35 & 0.045 \\
\hline HOMA - Index & $2.2 \pm 1.3$ & $1.7 \pm 1.0$ * & $\begin{array}{l}-0.5(-0.9 \\
-0.03)\end{array}$ & 0.04 & $2.1 \pm 1.2$ & $2.1 \pm 1.3$ & $\begin{array}{l}0.04 \\
(-0.22 \\
0.29)^{\circ}\end{array}$ & 0.77 & 0.049 \\
\hline \multicolumn{10}{|l|}{ Mineral profile } \\
\hline Potassium, $\mathrm{mEq} / \mathrm{L}$ & $4.2 \pm 0.3$ & $4.1 \pm 0.3$ & $\begin{array}{l}-0.1 \quad(-0.3 ; \\
0.03)\end{array}$ & 0.1 & $4.3 \pm 0.3$ & $4.0 \pm 0.3$ * & $\begin{array}{l}-0.3 \\
-0.2)\end{array}(-0.4$ & 0 & 0.048 \\
\hline
\end{tabular}


Citation: Sofi F, Ghiselli L, Dinu M, Whittaker A, Pagliai G, et al. (2016) Consumption of Buckwheat Products and Cardiovascular Risk Profile: A Randomized, Single-Blinded Crossover Trial. J Nutr Food Sci 6: 501. doi:10.4172/2155-9600.1000501

Page 5 of 8

\begin{tabular}{|c|c|c|c|c|c|c|c|c|c|}
\hline Calcium, mEq/L & $8.9 \pm 0.3$ & $8.9 \pm 0.3$ & $\begin{array}{l}-0.07 \\
(-0.2 \\
-0.09)\end{array}$ & 0.4 & $8.9 \pm 0.4$ & $9.0 \pm 0.3$ & $\begin{array}{l}0.09 \\
(-0.04 \\
0.2)\end{array}$ & 0.14 & 0.102 \\
\hline $\begin{array}{l}\text { Magnesium, } \\
\mathrm{mg} / \mathrm{dL}\end{array}$ & $2.0 \pm 0.1$ & $2.0 \pm 0.1$ & $\begin{array}{l}0.04 \\
(-0.02 \\
0.1)\end{array}$ & 0.15 & $2.0 \pm 0.1$ & $2.0 \pm 0.2$ & $\begin{array}{l}0.04 \\
(-0.03 \\
0.1)\end{array}$ & 0.23 & 1 \\
\hline Iron, mg/dL & $84.6 \pm 21.4$ & $76.3 \pm 25.1$ & $\begin{array}{l}-8.4 \\
(-20.0 \\
3.3)\end{array}$ & 0.14 & $89.3 \pm 27.8$ & $77.8 \pm 24.0$ & $\begin{array}{l}-11.5 \\
(-32.1 \\
9.0)\end{array}$ & 0.23 & 0.792 \\
\hline Sodium, & $138.8 \pm 2.0$ & $139 \pm 1.6$ & $\begin{array}{l}0.15(-0.9 ; \\
1.2)\end{array}$ & 0.77 & $139.4 \pm 2.2$ & $139.6 \pm 1.8$ & $\begin{array}{l}0.2 \\
1.1)\end{array}(-0.7 ;$ & 0.64 & 0.944 \\
\hline \multicolumn{10}{|c|}{ Oxidative stress profile } \\
\hline $\mathrm{MDA}, \mathrm{pg} / \mathrm{mL}$ & $49.9 \pm 30.5$ & $35.2 \pm 20.9$ * & $\begin{array}{l}-14.7 \\
(-23.5 \\
-6.0)\end{array}$ & 0 & $40.0 \pm 42.9$ & $38.0 \pm 33.7$ & $\begin{array}{l}-2.0 \\
(-21.8 \\
17.9)^{\circ}\end{array}$ & 0.83 & 0.276 \\
\hline $\begin{array}{l}\text { ROS- } \\
\text { Lymphocytes }\end{array}$ & $644 \pm 277.4$ & $551.1 \pm 258$ & $\begin{array}{l}-92.2 \\
(-193.6 \\
7.9)\end{array}$ & 0.06 & $531.7 \pm 179.5$ & $643.5 \pm 133.2$ * & $\begin{array}{l}111.8 \\
(13.1 ; \\
210.5)^{\circ}\end{array}$ & 0.03 & 0.015 \\
\hline ROS-Monocytes & $1163 \pm 444.4$ & $1244.2 \pm 380.6$ & $\begin{array}{l}81.2 \\
(-147.5 ; \\
309.9)\end{array}$ & 0.44 & $1045.5 \pm 358.4$ & $1253.3 \pm 296.9$ * & $\begin{array}{l}207.9(8.5 ; \\
407.2)\end{array}$ & 0.04 & 0.361 \\
\hline $\begin{array}{l}\text { ROS- } \\
\text { Granulocytes }\end{array}$ & $1642.5 \pm 656.6$ & $1762.2 \pm 566.8$ & $\begin{array}{l}119.7 \\
(-165.8 \\
405.2)\end{array}$ & 0.36 & $1380.6 \pm \pm 433.6$ & $1684.1 \pm 378.2$ * & $\begin{array}{l}303.5 \\
(12.6 ; \\
594.4)\end{array}$ & 0.04 & 0.376 \\
\hline TAC & $18.5 \pm 2.7$ & $20.3 \pm 2.9$ * & $\begin{array}{l}1.76(0.39 ; \\
3.12)\end{array}$ & 0.02 & $19.1 \pm 2.4$ & $19.3 \pm 2.2$ & $\begin{array}{l}0.25 \\
(-0.71 \\
1.2)^{\circ}\end{array}$ & 0.57 & 0.116 \\
\hline
\end{tabular}

Table 3: Modifications of biochemical and redox variables, measured before and after each respective replacement diet. Data are reported as mean and standard deviation. MDA=Malondialdehyde; ROS=Reactive Oxygen Species; TAC=Total Antioxidant Capacity. ${ }^{*} \mathrm{p}<0.05$ for paired T-test (pre vs post). ${ }^{\circ} \mathrm{p}<0.05$ for independent T-test (for changes between the buckwheat and control groups). $\dagger$ General linear model adjusted for age, gender, BMI, smoking habits, hypertension and dyslipidemia.

The changes in total and LDL cholesterol, and insulin were significantly different $(\mathrm{p}<0.05)$ between the two study arms. A similar result was shown for ROS production by lymphocytes. This was ascribed to improved values within the buckwheat group, with no significant changes in the control group (except for ROS production). Mean percentage change in lipid, gluco-metabolic and various oxidative stress-related parameters are shown in Figure 1.

The replacement diet with buckwheat products was found to result in a significant reduction $(\mathrm{p}<0.05)$ in plasma levels of total cholesterol (mean reduction: $-9.4 \mathrm{mg} / \mathrm{dL}$; $-4.7 \%)$, LDL cholesterol $(-10.4 \mathrm{mg} / \mathrm{dL}$; $-8.4 \%)$, as well as triglycerides $(-17 \mathrm{mg} / \mathrm{dL} ;-15 \%)$. Glucose levels and the HOMA-Index decreased significantly by $5.7 \%$ and $22.7 \%$ respectively $(-5.1 \mathrm{mg} / \mathrm{dL}$ and -0.5$)$. A reduction in the insulin levels was also observed $(-1.7 \mathrm{U} / \mathrm{L} ;-17 \%)$, although this was not significant. With regard to the oxidative stress profile, a significant amelioration in TBARs levels $(-14.7 \mathrm{pg} / \mathrm{mL} ;-29.5 \%)$ and an increase by $9.7 \%$ in antioxidant activity were reported. In contrast, no differences in any of these parameters were observed after the intervention period with control products. ROS production increased significantly in the control group, compared to the buckwheat intervention group (Table 3). Serum electrolyte content was not significantly changed after consumption of either the buckwheat-enriched products or the control products (results not shown).
With regard to the inflammatory parameters, monocyte chemotactic protein-1 (MCP-1) and macrophage inflammatory protein-1beta (MIP-1beta) were significantly reduced after consumption of both buckwheat-enriched products and the control (Table 4). There were no further improvements in the inflammatory profile of the buckwheatenriched products over that of the control (Table 4).

\section{Discussion}

The aim of the present study was to investigate whether a twomonth replacement diet using common buckwheat (Fagopyrum esculentum)-enriched wheat food products on an Italian population (at risk for cardiovascular problems) could provide additive protective effects in reducing cardiovascular risk factors, including blood glucose, insulin, lipids, oxidative damage and pro-inflammatory markers. Hence, the objective was to investigate potential hypocholesterolemic, hypoglycemic, anti-oxidant and anti-inflammatory effects, considered important in reducing CVD risk.

Most studies conducted to date, have investigated the effect of various buckwheat extracts or individual molecular components on cell lines and animal models, with relatively few studies being performed on humans. [5] The present study provided a valuable contribution in this context, particularly with regard to investigating the potential anti-inflammatory effect. Of relevance, it was possible to 
examine the above-mentioned parameters, after the consumption of the buckwheat-enriched wheat as the staple carbohydrate source in the diet. The effects were then compared with those obtained after the consumption of modern wheat alone on the same population of Italian individuals, traditionally accustomed to wheat as a staple carbohydrate source. The results showed a positively impact on CVD risk by downregulating several key parameters associated with the disease.

Consumption of the buckwheat-enriched wheat products displayed hypocholesterolemic effects, including the significant reduction of total cholesterol and LDL-cholesterol, as well as a decrease in the triglyceride content. This effect was not observed after the consumption of the modern wheat alone. Given that LDL is the predominant cholesterol risk factor for CVD [9], successful dietary/ lifestyle treatments aimed at reducing this parameter are warranting of attention in primary prevention. Various mechanisms, including decreased lipid absorption and effects on lipid metabolic enzymes have been proposed but the individual buckwheat compounds responsible for the underlying effects are unknown [5].

Buckwheat is also considered a low glycemic index (GI) food, and it has been shown that low-GI diets promote significantly improved lipid profiles in medium- and longer-term interventions, particularly with regard to reducing both total cholesterol and LDL-cholesterol levels [10-12]. Of the many potential mechanisms in regulating glucose levels, buckwheat is renowned for containing various bioactive substances (such as d-chiro-inositol, and various polyphenols), which have been shown to be exercise a positive impact on either insulin or glucose metabolism in animal models [4]. The present study verified positive cholesterol-lowering and hypoglycemic effects after only two months of consumption. The hypoglycemic effect was evident from the significant reduction in the HOMA-index, reflecting the respective decreases in glucose and insulin. Maintenance of glucose homeostasis, by targeting lifestyle interventions, is an essential primary prevention strategy towards preventing the development of type 2 diabetes mellitus [13] and in reducing CVD risk.

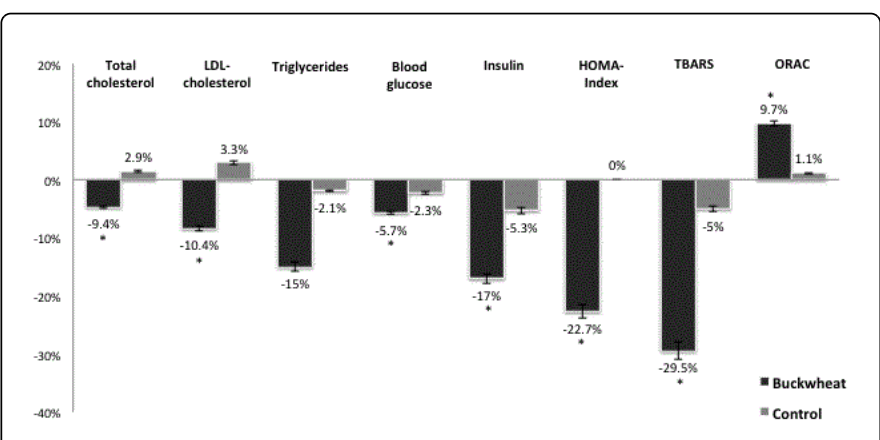

Figure 1: Mean percentage of change in serum levels of lipid parameters, glucometabolic parameters, thiobarbituric acid reactive substances (TBARS) and oxygen radical absorbance capacity (ORAC) with buckwheat products versus control products after 8 weeks of dietary intervention $\left({ }^{\star} \mathrm{p}<0.05\right)$.
In addition, the results from the present dietary trial showed that consumption of buckwheat-enriched products were able to improve circulatory TAC, thereby corroborating previous work showing the efficacy of short-term interventions on this parameter using $30 \%$ buckwheat-enriched bread [14]. An improved TAC following consumption of buckwheat was suggested to be attributable to bioactive peptide fragments capable of stabilizing ROS, and the elevated polyphenol content [4]. A significantly higher polyphenol content and anti-radical activity was evident in the buckwheatenriched semolina and flour, compared to the modern wheat control. Therefore, it is highly probable that the improved TAC and reduced lipid peroxidation damage were associated with the well-documented antioxidant benefits attributed to buckwheat [5].

Monocyte chemotactic protein-1 (MCP-1) and macrophage inflammatory protein-1beta (MIP-1beta) were significantly reduced after consumption of both buckwheat-enriched products and the control. Previous work published by this group [7], similarly showed improvements in MCP-1 and MIP-1beta in a healthy population, after two-month period, following the consumption of both khorasan wheat and the same modern control products. However, consumption of buckwheat-enriched products did not result in any additional improvements to the inflammatory profile. The present study represents one of the very few conducted to investigate potential antiinflammatory benefits of buckwheat, and is novel being an in vivo study on humans. Polyphenols have been reported to exert antiinflammatory activity via the modulation of the oxygen-stress-sensitive nuclear factor $(\mathrm{NF}-\mathrm{kB})$, which mediates the expression of important pro-inflammatory cytokines such as TNF-alpha, Il-6 and VEGF [2]. Notwithstanding, the significantly higher polyphenol content and antiradical activity of the buckwheat-enriched semolina and flour (in comparison to the modern wheat) it would appear that within the framework of the present study, the beneficial effects may be limited to traditional anti-oxidant activity. However, more studies on humans are warranting.

Given that the study population was relatively small in size, studies on a larger population are needed to verify the present results. However, there were overall significant changes in various parameters, which could be independently attributed to the replacement diet. Body weight did not change significantly after the trial, thereby showing that patients adhered to their normal habits relating to carbohydrate consumption. Hence, the beneficial effects were not associated with weight loss, but rather with the ingestion of buckwheat-enriched wheat products.

In conclusion, a replacement diet with buckwheat-enriched products impacted positively by down-regulating several key parameters associated with CVD risk, including total cholesterol, LDLcholesterol, blood glucose, insulin, and the HOMA index. No improvements in the inflammatory profile were observed in the present studies that were specifically related to the consumption of buckwheat products. Additional research is necessary to further investigate the possible beneficial effect of this pseudo-cereal.

\begin{tabular}{|l|l|l|l|l|l|l|l|}
\hline \multirow{2}{*}{ Variables } & \multicolumn{2}{|l|}{ Buckwheat } & p $\dagger$ & Control & \multicolumn{2}{l|}{$\begin{array}{l}\text { for } \\
\text { changet }\end{array}$} \\
\cline { 2 - 6 } & pre & post & change & pre & post & change & \\
\hline
\end{tabular}


Citation: Sofi F, Ghiselli L, Dinu M, Whittaker A, Pagliai G, et al. (2016) Consumption of Buckwheat Products and Cardiovascular Risk Profile: A Randomized, Single-Blinded Crossover Trial. J Nutr Food Sci 6: 501. doi:10.4172/2155-9600.1000501

Page 7 of 8

\begin{tabular}{|c|c|c|c|c|c|c|c|c|c|}
\hline $\begin{array}{l}\text { Interleukin-1ra, } \\
\mathrm{pg} / \mathrm{mL}\end{array}$ & $25.5 \pm 39.1$ & $17.3 \pm 16.3$ & $\begin{array}{ll}-8.2 & (-22.1 ; \\
5.7) & \end{array}$ & 0.2 & $39.5 \pm 100.9$ & $25.4 \pm 55.8^{*}$ & $\begin{array}{l}-14.1(-38.9 ; \\
10.6)\end{array}$ & 0.22 & 0.3 \\
\hline $\begin{array}{l}\text { Interleukin-4, } \\
\mathrm{pg} / \mathrm{mL}\end{array}$ & $0.3 \pm 0.3$ & $0.3 \pm 0.3$ & $\begin{array}{l}-0.08 \quad(-0.2 \\
0.02)\end{array}$ & 0.09 & $0.4 \pm 0.3$ & $0.3 \pm 0.3$ & $\begin{array}{l}-0.04 \\
0.03)\end{array}$ & 0.23 & 0.465 \\
\hline $\begin{array}{l}\text { Interleukin-6, } \\
\mathrm{pg} / \mathrm{mL}\end{array}$ & $3.2 \pm 1.7$ & $3.2 \pm 1.7$ & $\begin{array}{ll}-0.05 & (-0.9 ; \\
0.8) & \end{array}$ & 0.89 & $3.7 \pm 2.2$ & $2.8 \pm 1.6$ * & $\begin{array}{ll}-0.9 & (-1.3 ; \\
-0.5) & \end{array}$ & 0 & 0.033 \\
\hline $\begin{array}{l}\text { Interleukin-8, } \\
\mathrm{pg} / \mathrm{mL}\end{array}$ & $28.3 \pm 33.3$ & $18.6 \pm 27.1^{*}$ & $\begin{array}{l}-9.7 \quad(-20.7 ; \\
1.3)\end{array}$ & 0.07 & $23.8 \pm 29.9$ & $29 \pm 60.2$ & $\begin{array}{l}5.2 \\
24.2)\end{array}(-13.8$ & 0.55 & 0.142 \\
\hline $\begin{array}{l}\text { Interleukin-10, } \\
\mathrm{pg} / \mathrm{mL}\end{array}$ & $5.3 \pm 2.6$ & $5 \pm 3.5$ & $\begin{array}{l}-0.3 \\
1.2)\end{array}$ & 0.67 & $7.7 \pm 9.1$ & $4.5 \pm 3.2^{*}$ & $\begin{array}{l}-3.1 \\
0.5)\end{array}$ & 0.07 & 0.172 \\
\hline $\begin{array}{l}\text { Interleukin-12, } \\
\mathrm{pg} / \mathrm{mL}\end{array}$ & $10.7 \pm 4.6$ & $9 \pm 4.1$ & $\begin{array}{l}-1.7 \quad(-4.2 ; \\
0.8)\end{array}$ & 0.15 & $12.7 \pm 6.8$ & $9.4 \pm 4$ * & $\begin{array}{l}-3.3 \quad(-5.1 ; \\
-1.5)\end{array}$ & 0 & 0.329 \\
\hline $\begin{array}{l}\text { Interleukin-17, } \\
\mathrm{pg} / \mathrm{mL}\end{array}$ & $3.1 \pm 2.1$ & $2.8 \pm 2.3$ & $\begin{array}{ll}-0.4 & (-1.5 ; \\
0.7) & \end{array}$ & 0.44 & $3.5 \pm 1.7$ & $2.7 \pm 1.6$ & $\begin{array}{ll}-0.8 & (-1.8 \\
0.1) & \end{array}$ & 0.09 & 0.498 \\
\hline $\mathrm{lp}-10, \mathrm{pg} / \mathrm{mL}$ & $871.8 \pm 677.7$ & $785.6 \pm 489.4$ & $\begin{array}{l}-86.2 \\
(-276.5 \\
104)\end{array}$ & 0.32 & $867.4 \pm 529.5$ & $888.4 \pm 504.2$ & $\begin{array}{l}21.1 \text { (121.9; } \\
164.1)\end{array}$ & 0.74 & 0.369 \\
\hline MCP-1, pg/mL & $57.1 \pm 38.4$ & $47.2 \pm 29.9$ * & $\begin{array}{ll}-9.9 & (-18.1 ; \\
-1.6) & \end{array}$ & 0.02 & $51.7 \pm 30.5$ & $42.5 \pm 26.2$ & $\begin{array}{l}-9.2 \quad(-14.2 ; \\
-4.3)\end{array}$ & 0 & 0.857 \\
\hline MIP-1 beta, $\mathrm{pg} / \mathrm{mL}$ & $172.8 \pm 93.4$ & $142.2 \pm 60.6$ * & $\begin{array}{l}-30.6(-53.7 \text {; } \\
-7.4)\end{array}$ & 0.01 & $167.5 \pm 64.7$ & $143.9 \pm 64.4$ & $\begin{array}{ll}-23.6 & (-40 ; \\
-7.2) & \end{array}$ & 0.02 & 0.513 \\
\hline TNF-alpha, pg/mL & $6.1 \pm 3.4$ & $6.7 \pm 7.1$ & $\begin{array}{l}0.6 \\
4.5)\end{array}$ & 0.74 & $9.1 \pm 7.2$ & $6.6 \pm 4.2$ & $-2.5(-6 ; 0.9)$ & 0.12 & 0.226 \\
\hline VEGF, pg/mL & $83.3 \pm 36.1$ & 76. \pm 36.1 & $\begin{array}{l}-6.4 \quad(-18.2 ; \\
5.3)\end{array}$ & 0.24 & $84 \pm 32.8$ & $73.4 \pm 37.9$ * & $\begin{array}{l}-10.6(-23.4 \\
2.3)\end{array}$ & 0.09 & 0.502 \\
\hline
\end{tabular}

Table 4: Modifications in the inflammatory profile. Ip-10=Interferon Gamma-Induced Protein 10; MCP-1=Monocyte Chemotactic Protein-1; MIP-1 beta=Macrophage Inflammatory Protein-1 beta; TNF-alpha=Tumour Necrosis Factor-alpha; VEGF=Vascular Endothelial Growth Factor Data are reported as mean and standard deviation. ${ }^{*} \mathrm{p}<0.05$ for paired T-test (pre vs post). †General linear model adjusted for age, gender, BMI, smoking habits, hypertension and dyslipidemia.

\section{Acknowledgement}

The research was financed by the "Regione Umbria" (Italy) through the project entitled "SARACENO-UMBRIA" Act 1.2.4 PSR Umbria 2007-2013; thanks to Ente Cassa di Risparmio di Firenze which contributed to the acquisition of a part of the instrumentation used for this work. Particular thanks are extended to the farms: Coccia Sante Azienda Agricola (project leader) and Di Camillo Francesco Azienda Agricola for the buckwheat production.

\section{References}

1. Kennedy ET (2006) Evidence for nutritional benefits in prolonging wellness. Am J Clin Nutr 83: 410S-414S.

2. Santangelo C, Varì R, Scazzocchio B, Di Benedetto R, Filesi C, et al. (2007) Polyphenols, intracellular signalling and inflammation. Ann Ist Super Sanita 43: 394-405.

3. World Health Organisation (2015) Cardiovascular diseases (CVDs).

4. Zhang ZL, Zho ML, Tang Y, Li FL, Tang YX, et al. (2012) Bioactive compounds in functional buckwheat food. Food Res Int 49: 389-395

5. Giménez-Bastida JA, Zieliński H (2015) Buckwheat as a Functional Food and Its Effects on Health. J Agric Food Chem 63: 7896-7913.

6. Zhang HW, Zhang YH, Lu MJ, Tong WJ, Cao GW (2007) Comparison of hypertension, dyslipidaemia and hyperglycaemia between buckwheat seed-consuming and non-consuming Mongolian-Chinese populations in Inner Mongolia, China. Clin Exp Pharmacol Physiol 34: 838-844.

7. Sofi F, Whittaker A, Cesari F, Gori AM, Fiorillo C, et al. (2013) Characterization of Khorasan wheat (Kamut) and impact of a replacement diet on cardiovascular risk factors: cross-over dietary intervention study. Eur J Clin Nutr 67: 190-195.

8. Becatti M, Marcucci R, Bruschi G, Taddei N, Bani D, et al. (2014) Oxidative modification of fibrinogen is associated with altered function and structure in the subacute phase of myocardial infarction. Arterioscler Thromb Vasc Biol 34: 1355-1361.

9. Martín-Timón I, Sevillano-Collantes C, Segura-Galindo A, Del CañizoGómez FJ (2014) Type 2 diabetes and cardiovascular disease: Have all risk factors the same strength? World J Diabetes 5: 444-470.

10. Sloth B, Krog-Mikkelsen I, Flint A (2004) No difference in body weight decrease between a low-glycemic-index and a high-glycemic-index diet but reduced LDL cholesterol after 10-wk ad libitum intake of the lowglycemic-index diet. Am J Clin Nutr 80: 337-347

11. de Rougemont A, Normand S, Nazare JA, Skilton MR, Sothier M, et al. (2007) Beneficial effects of a 5-week low-glycaemic index regimen on weight control and cardiovascular risk factors in overweight non-diabetic subjects. Br J Nutr 98: 1288-1298.

12. Tovar J, Nilsson A, Johansson M, Björck I (2014) Combining functional features of whole-grain barley and legumes for dietary reduction of cardiometabolic risk: a randomised cross-over intervention in mature women. Br J Nutr 111: 706-714. 
Citation: Sofi F, Ghiselli L, Dinu M, Whittaker A, Pagliai G, et al. (2016) Consumption of Buckwheat Products and Cardiovascular Risk Profile: A Randomized, Single-Blinded Crossover Trial. J Nutr Food Sci 6: 501. doi:10.4172/2155-9600.1000501

Page 8 of 8

13. Authors Evans JL, Balkan B, Rushakoff RJ (2013) Oral and Injectable (Non-insulin) Pharmacological Agents for Type 2 Diabetes. Oral and Injectable (Non-insulin) Pharmacological Agents for Type 2 Diabetes .
14. Bojnanská T, Francáková H, Chlebo P, Vollmannová A (2009) Rutin content in buckwheat enriched bread and influence of its consumption on plasma total antioxidant status. Czech J Food Sci 27: S236-S240. 